\title{
Salinity stress resistance in wheat
}

Muniba Nazir

Microbiology Lab, Department of Zoology, GC University, Lahore, Pakistan

\begin{tabular}{|c|c|c|c|c|}
\hline $\begin{array}{l}\text { Authors' } \\
\text { Contribution }\end{array}$ & \multicolumn{4}{|c|}{ Nazir, M wrote the entire manuscript. } \\
\hline \multicolumn{2}{|c|}{ "Corresponding Author's Email Address } & iramliaq@hotmail.com & & iew Proccess: Double-blind pee \\
\hline \multicolumn{2}{|c|}{ Received: 17 June 2021} & Revised: 31 July 2021 & Accepted: 10 August 2021 & \\
\hline \\
\hline \multicolumn{5}{|c|}{$\begin{array}{rr}\text { Digital Object Identifier (DOI) Number: } & \text { https://dx.doi.org/10.33865/wj } \\
& \text { ABSTRACT } \\
\end{array}$} \\
\hline \multicolumn{5}{|c|}{$\begin{array}{l}\text { Wheat is used as staple food worldwide and it ranked third in cereals. Its productivity a the global level decreases by many } \\
\text { stresses mainly by salinity stress which is associated with different physiological and biochemical processes of plants. To } \\
\text { overcome these growth and yield reduction issues, salinity resistance in wheat can be achieved. The introduction of resistance } \\
\text { to salinity-induced water stress and ion toxicity in wheat lead to more reliable results. Salt tolerance mechanisms at tissues } \\
\text { and whole plant levels along with sequestration of toxic ions can improve overall growth, yield, and salinity resistance } \\
\text { capability in wheat. Different sources and measurements of salinity play important role in the production of salinity tolerant } \\
\text { wheat. This article mainly reviews different physiological mechanisms, genetics, omics, and quality trait loci approaches for the } \\
\text { production of salinity tolerant wheat. }\end{array}$} \\
\hline
\end{tabular}

\section{Keywords: Salinity resistance, salt tolerance, wheat, $\mathrm{NaCl}$, osmotic stress.}

INTRODUCTION: Wheat (Triticum aestivum) is regarded as one of the major food components worldwide and is belonged to the family Poaceae. Its cultivation was reported from the Middle East about 8000 years ago which expanded readily throughout the world (De Vries et al., 2018). The global production of wheat is categorized third following rice and maize and it produces $35 \%$ of total food grains in the world (Khan et al., 2017). By virtue of different reasons including a reduction in cultivated land, heat, chilling, heavy metal, waterlogging, drought, chemical stress, and other abiotic and biotic stresses causes a reduction in wheat cultivation (Masuda, 2016). Large parts of the world are inclined to different levels of salinity stress from sodic saline-sodic to saline soils which cause adverse effects on plant growth, development, and yield. Osmotic components of salinity-induced cell reduced the hydration level of that cell which ultimately causes stomatal closure, photosynthesis inhibition, senescence, and cell expansion. Soil salinity is a major abiotic stress in the world. Around $20 \%$ of total agricultural fields are subjected to salinity which caused a 50\% reduction in wheat yield along with the influence of other stresses (Miransari and Smith, 2019; Munns et al., 2020). Wheat is not well tolerant to salinity stress as compared to its relatives, because at salinity level of $6-8 \mathrm{dSm}-1$, causes a reduction in yield. To cope with this issue it is critical to developing methods and techniques for the production of salinity-resistant and tolerant wheat varieties (Miransari and Smith, 2019). Salt deposition with different amounts in the soil is the cause of different salinity levels. The main cause salt deposition is irrigation of soil with saline water (Iqra et al., 2020). As wheat is used as staple food and salinity is increasing continuously in Pakistan and it may also be estimated that this rate of salinity will double in the incoming years. So to cope with these issues, there should be well aware of salinity resistance mechanisms and genetics to produce salinity resistant wheat plants, salinity affects all the physiological and biochemical functions of plants (Iqra et al., 2020). So the development of salt-tolerant wheat and interpretation of salinity resistant mechanism in wheat is of great importance (Xiong et al., 2017).

OBJECTIVES: The objective of the present study was to evaluate different mechanisms, sources, new proportions of salinity resistance, and, its improvement by different genetic and breeding approaches.

SALINITY RESISTANCE IN WHEAT: Salinity resistance may originate from resistance to osmotic stress and salinity-induced ion toxicity. Being a glycophytes crop, wheat responds in the saline environment at a different pace as compared with halophytes. The accumulation of saline water causes osmotic stress and thereby decreasing the water potential in plants which results in greater yield loss. SOS1 is a cell membrane $\mathrm{Na}^{+} / \mathrm{H}^{+}$antiporter which is responsible for the exclusion of sodium from the cytoplasm. $\mathrm{SOS}_{2}$; the serine-threonine type protein kinases (CIPK24) interact with SOS3 to regulate $\mathrm{Na}+/ \mathrm{H}+$ exchanger SOS1, therefore this pathway is known as the salt resistance pathway (Xiong et al., 2017). The wheat plant utilizes phenotypic plasticity to overcome the effect of salinity stress by upregulation of different salt responsive genes including ion transporters, signaling pathways, osmolyte production, transcriptional responsive genes, and antioxidant enzymes.

Resistance to salinity induced water stress: While wheat cultivation the quantity and quality of water is taken as an important parameter that affects wheat yield production. Saline water irrigation causes osmotic stress by affecting the level of organic solutes and inorganic ions $\left(\mathrm{Na}^{+}, \mathrm{Cl}^{-}, \mathrm{K}^{+}\right.$, etc.) and also causes more severe water deficiency in wheat. The results of a study indicate that the osmotic potential pressure significantly increases in salinity-resistant wheat genotypes as compared to sensitive ones. Osmoregulation is a common response and is an important mechanism in salinity-resistant wheat as it causes leaf desiccation avoidance and other consequences of turgor loss. In wheat, salinity stress is important to determine the 
osmotic adjustment of the plant under salinity. By determining the $\mathrm{Na}^{+}$toxicity and $\mathrm{NaCl}$ osmotic potential of wheat, it is confirmed that $\mathrm{Na}+$ exclusion from leaves is an important mechanism to produce tolerant wheat varieties. The production of sugars under salt stress results in the adjustment of osmotic potential. Sugars, organic acids, Polyols, and many amino acids are also involved in the Osmoregulation mechanism in wheat and also protect the enzymes and cellular components during stress and make the plants more resistant to salinity (Guo et al., 2015). Osmoregulation allows turgor maintenance by reducing water loss while maximizing water uptake and leaf desiccation avoidance and results in greater leaf growth and stomatal conductance which make wheat plants more resistant to salinity stress.

Resistant to salinity induced ion toxicity: Salinity stress causes hyper ionic and hyperosmotic stress in wheat which causes a nutrient disturbance, hormonal imbalance, and other negative impacts on wheat growth and yield (Daneshbakhsh et al., 2013). Resistance to salinity-induced ion toxicity in wheat occurs by reduced ion uptake mechanism, ion exclusion mechanism, salinity tolerance, and by genetic engineering techniques (Wang and Xia, 2018). It has long been conferred that bread wheat is more salt-tolerant than tetraploid wheat. This difference is because of the maintenance of a higher ratio of $\mathrm{K}^{+}$concentration in leaves of bread wheat (Wang and Xia, 2018). Wheat plants have adapted several mechanisms to reduce ionic and osmotic stresses of salinity and tissue tolerance by $\mathrm{Na}+$ exclusion from flag leaves.

Ion exclusion mechanism in wheat: There are different ion exclusion mechanisms in different plants. In the case of wheat HKT genes are involved in $\mathrm{Na}^{+}$exclusion and $\mathrm{Na}^{+}$transport regulation in wheat. These genes control $\mathrm{Na}^{+}$unloading from the xylem in root and sheath cells of wheat. In addition, these genes also involved in reduced $\mathrm{Na}^{+}$content in leaves. Some genes are involved in $\mathrm{Na}^{+}$exclusion from the xylem which is responsible for lesser uptake of $\mathrm{Na}^{+}$in leaves and results in an increase in wheat grains (Miransari and Smith, 2019). The result of a study also showed that the natural diversity of ancestral wheat germplasm also improves wheat tolerance against salinity by $\mathrm{Na}^{+}$exclusion. HKT transporters play important role in the vacuolar sequestration of $\mathrm{Na}^{+}$which is an important cost-effective strategy for wheat plants (Tiwari et al., 2020).

Salt tolerance mechanism in wheat: Crops exhibit salinity tolerance in three ways, i.e., ion exclusion mechanisms; in which toxic ions are excluded from different plant parts, tissue tolerance in which toxic ions are compartmentalized into different plant tissues, the third is shoot ion- independent tolerance which is responsible for independent $\mathrm{Na}^{+}$ accumulation in tissues as well as water uptake and growth of the plant (Munns et al., 2020).

$\mathrm{Na}+$ exclusion: $\mathrm{Na}^{+}$accumulation in the cytoplasm can be controlled by reduced $\mathrm{Na}^{+}$influx, increased $\mathrm{Na}^{+}$efflux, and vacuolar sequestration of $\mathrm{Na}^{+}$ions (Tiwari et al., 2020). This process is controlled by SOS1, SOS2, SOS3 (salt overly sensitive) pathways and by the activity of different pumps such as $\mathrm{H}^{+}$ ATPase pump. $\mathrm{Na}^{+}$and $\mathrm{Cl}^{-}$require compartmentalization at the cellular and intracellular levels to avoid the harmful impact of salinity on wheat growth and yield. $\mathrm{Na}+$ exclusion mechanism is also responsible for its storage root cell vacuoles. It was also investigated that the QTL for Na+ exclusion mechanism reduces negative effects of salinity of wheat grain quality. The introduction of the NaX2 gene in the durum wheat from the Triticum monococcum lead to the decreased $\mathrm{Na}+$ content in the durum wheat which will produce more resistant wheat verities.

Salinity counter-mechanisms in wheat via different signaling pathways: The cell membranes in wheat plants are served with salinity $\mathrm{Na}+$ receptors, which receive salinity stress signals and enhance the signaling molecules like $\mathrm{Ca} 2+$, hormones, ROS etc. By the elicitation of these molecules, three pathways will operate in wheat cells that ultimately regulate the SOS1 for pumping out of $\mathrm{Na}+$ from the cytosol. For these mechanisms, all the SOS1 related genes were up-regulated. The activity of $\mathrm{K}+$ and $\mathrm{Na}^{+}$transporters and proton pumps along SOS2 and SOS3 protein kinase pathways coordinate with SOS1 for sequestration and secretion of toxic $\mathrm{Na}+$ out of cells (Shah et al., 2017).

$\mathrm{K}+$ retention in mesophyll cells: Potassium is an important nutrient which can control wheat development and growth under salinity stress. Potassium retention in mesophyll cells is an important strategy to control salinity stress by increasing tolerance capacity in wheat. A case study by using durum wheat and bead wheat genotypes was conducted and results showed that the ratio of $\mathrm{K}+/ \mathrm{Na}+$ was a good indicator of salinity tolerance in bread wheat (Karthik et al., 2014).

Salinity tolerance at whole-plant level: Salinity tolerance not only occurs at the tissue level but it also occurs at whole-plant level. At the whole plant level salinity tolerance can be achieved by alteration of flowering and fruiting times, retranslocation of photosynthates, allocation of leaf salt to leaf petiole or sheath, allocation of salts at epidermis instead of mesophyll cells, control of restoration of salts in the wheat stem, salt excretion via roots, salt removal from xylem and symbiotic association are the commonly studied phenomena in wheat plants (Isfahani et al., 2018).

IMPROVEMENT OF SALINITY TOLERANCE IN WHEAT BY SILICON: Silicon is the second most abundant element on earth. It is not yet classified as an essential element but it plays important role in the improvement of salinity tolerance in wheat plants. Silicon has been reported to improve salinity tolerance mechanisms in wheat by application a small amount of soluble silicon (Miransari and Smith, 2019).

GENETICS OF SALINITY RESISTANCE IN WHEAT: Wheat exhibits multigenic traits which are more complex than other well-studied relatives. When wheat plants are exposed to different salinity stresses, many genes are activated to mediate different resistance mechanisms for the survival of plants. Some genes in wheat are activated for the synthesis of Phytohormones such as activation of TaAOC1 gene in wheat for the synthesis of jasmonic acid during salinity stress for regulation of resistance mechanisms (Zhao et al., 2014). In the same way Overexpression of the TaBASS2 gene improves salinity tolerance in wheat via ABA signaling (Zhao et al., 2016). $\mathrm{Na}+$ exclusion conciliated by HKT genes has been playing a major salinity tolerance mechanism in wheat. The genes such as TaHKT1; 5-D were explored in salinity mediated mechanisms along with TaHKT1;5-B1 and TaHKT1; 5-B2 transcripts (Byrt et al., 2014). Studies on wheat plants suggested that ROS homeostasis is the major biochemical factor for salinity tolerance. TaSR01 gene play important role In ROS homeostasis 
in wheat and is predicted to affect PARP catalytic activity which is significant for DNA repair in salinity stress. TaCHP; a zink finger transcription factor that facilitates salinity tolerance in wheat through improved peroxidase leaf activity for the enhancement of ROS scavenging mechanisms. The salt tolerance gene SOS3 is indicated to encode calcium-binding protein with $\mathrm{N}$-myristoylation signature sequence. The resultant gene products of SOS3 are predicted to use for the operation of SOS2 and SOS1 gene. It was also suggested that an increase in mRNA synthesis collaborates with the activation of the SOS3 gene in wheat during salinity stress (Tiwari et al., 2020). In wheat, VHA-A transcripts are up-regulated in response to salinity stress. In the same way, NAC gene from wheat was also studied and considered to have possible physiological and morphological roles in salinity stress. The results of a study based on Nax genes associated with high sodium accumulation in wheat reveal that Nax genes play important role in osmotic stress (Genc et al., 2019). The Overexpression of allene oxide cyclase in wheat causes an increase in jasmonate contents lead toward improved salinity resistance (Xiong et al., 2017). Transcription factor families

\begin{tabular}{|c|c|c|c|c|}
\hline Gene & Group & specification & NaCl concentration & References \\
\hline CBL2 & Stress sensor & Ca sensor kinase & $250 \mathrm{mM}$ & Goyal et al. (2016) \\
\hline NHX1 & Ion balance regulator & Na transporters & $100 \mathrm{mM}-250 \mathrm{mM}$ & Formentin et al. (2018) \\
\hline CLC & Ion balance regulators & Chloride anion channel & $150-200 \mathrm{mM}$ & Formentin et al. (2018) \\
\hline GLXR, ERD4 & Ion balance regulators & Cation channels & $200 \mathrm{mM}-300 \mathrm{mM}$ & Xiong et al. (2017) \\
\hline GST & Ion balance regulators & Transferases & $150 \mathrm{mM}-255 \mathrm{~mm}$ & Goyal et al. (2016) \\
\hline APX & ROS regulators & ROS scavengers & $50 \mathrm{mM}-255 \mathrm{mM}$ & Hemida et al. (2014) \\
\hline CAT & ROS regulators & ROS scavengers & $25 \mathrm{mM}-255 \mathrm{mM}$ & Hemida et al. (2014) \\
\hline SOD & ROS regulators & ROS scavengers & $50 \mathrm{mM}-250 \mathrm{mM}$ & Hemida et al. (2014) \\
\hline GR & ROS regulators & Redox enzymes & $100 \mathrm{mM}-150 \mathrm{mM}$ & Hemida et al. (2014) \\
\hline LOX & ROS regulators & Redox enzymes & $300 \mathrm{mM}$ & Xiong et al. (2017) \\
\hline PAO & ROS regulators & Redox enzymes & $50 \mathrm{mM}-250 \mathrm{mM}$ & Zarza et al. (2017) \\
\hline TASRO1 & ROS homeostasis & Catalytic enzyme & ---- & Liu et al. (2014) \\
\hline TaBASS2 & Salinity tolerance & ABA regulators & ---- & Zhao et al. (2014) \\
\hline P5CR & Cell protectors & Proline synthesis & $100 \mathrm{mM}-250 \mathrm{~mm}$ & Nounjan et al. (2012) \\
\hline $\mathrm{ADC}$ & Cell protectors & Polyamine synthesis & $100 \mathrm{mM}-250 \mathrm{mM}$ & Xiong et al. (2017) \\
\hline
\end{tabular}

Table 1: list of genes which change their expression level under salinity stress in Triticum aestivum.

Breeding approaches for salinity tolerant in wheat: The genetic pool of wheat has a huge amount of genetic diversity for salinity resistance as well as tolerance. During the last few decades, different breeding approaches for confirmation of salinity resistance in wheat have progressed so far. The cDNA, microarray, proteomics, genomics, subtraction hybridization techniques, and many other new techniques are used in this regard. The other most useable techniques are improved genotype assays in form of SNP arrays, next-generation turnover methods, gene editing tools to manipulate genetic effects, and other new phenomic platforms for elucidation of salinity effects in wheat. These techniques are used for the efficient utilization of salinity tolerance and resistance encoding genes in the wheat plant from different recourses (Wang and Xia, 2018). NEW PROPORTION IN SALINITY RESISTANCE MECHANISM OF WHEAT: Omics web: The rapid increase in proteomics, transcriptomics, genomics, epigenomics, and other omics, and advances in whole wheat genomics will stimulate more gene discovery in wheat for improvement of salinity resistance. For the identification of salinity tolerance in wheat cDNA microarrays between salt-tolerant and salt-susceptible wheat, such as MYB, WRKY, bHLH, AP2/ERF, NAC, and bZIP are readily engaged in salinity stress responses (Karthik et al., 2014). Recently some RNA sequencing techniques are used to elaborate transcriptomes of wheat under salt stress. It has also been found that the V-ATPase gene is involved in providing energy for the formation of a proton gradient to drive $\mathrm{Na}+$ into vacuoles. In the same way, $\mathrm{Cb} 1$ interacting protein kinases proteins play role in salt tolerance signaling in wheat. MYB transcription factors and TARSL4 genes are involved with root development and play an important part in the salt tolerance resistance mechanism in wheat (Zhang et al., 2016).

MEASUREMENTS AND SOURCES OF SALINITY RESISTANCE IN WHEAT: The successful breeding program of salinityresistant wheat depends upon the reliable estimation of plants. This measurement depends upon reliable techniques and a controlled level of salinity. The sources of salinity resistance mainly consist of commonly cultivated varieties of wheat, germplasm collection, soma clones, transgenes, and related wild relatives of wheat which can be used in various patterns and combinations by the use of prevalent and modern techniques (Zhang et al., 2016). techniques (Wang and Xia, 2018). But the absence of the whole genome sequence of wheat srestricts discovery of new salinity tolerance encoding genes. By using high throughput transcriptome sequencing and wheat cultivars with different levels of salinity tolerance, allows global gene expression following salinity stress. The expression of tandem and homologous duplications contributing to various salinity tolerance mechanisms in wheat was also analyzed by analysis of transcripts via genome survey sequencing methods. In the same way, rapid improvement in the next-generation sequencing and genomic enrichment information allows epigenomics identification in the salinity tolerance mechanism of wheat. Moreover for the further investigation of population genetics, multiple omics, and salt-tolerant QTL analysis is essential for the better output of salinity-resistant wheat varieties (Wang and Xia, 2018).

Production of salinity resistant germplasm: Including salinity-resistant diploid germplasm and somatic hybridization interrogation along with much other specific germplasm for salinity, resistance is used with the elaboration of two main 
mechanisms (ROS homeostasis and ionic control mechanism). For the production of salinity-resistant germplasm for gene discovery and genetic breeding, there is a need for a more elegant system. There is another recent trend in functional genomics is the establishment of comprehensive mutant libraries of hexaploid and tetraploid wheat. Salinity tolerant involving genes are easily identified from these comprehensive mutant libraries which help in the formulation of more durable salinity resistant varieties (Wang and Xia, 2018). The salinityresistant germplasm contains all the respective genes which enhance direct salinity tolerance mechanisms in wheat, or indirectly influence plant salinity tolerance by regulating different crosstalk pathways (Wang and Xia, 2018).

CONCLUSION: The present study illustrates importance of wheat as major food crop and different resistance mechanisms against salinity stress. It was also concluded that the salt tolerance mechanisms protect wheat plant by ion exclusion mechanism, tissue tolerance, and other salinity tolerance mechanisms. By using multi-genetic traits and different breeding approaches such as omics web and production of salinity-resistant germplasm salinity stress resistance can be achieved in wheat plants.

CONFLICT OF INTEREST: The authors declare no conflict of interest.

REFERENCES: Byrt, C. S., B. Xu, M. Krishnan, D. J. Lightfoot, A. Athman, A. K. Jacobs, N. S. Watson-Haigh, D. Plett, R. Munns and $\mathrm{M}$. Tester, 2014. The Na+ transporter, Ta hkt 1; 5-d, limits shoot na+ accumulation in bread wheat. The plant journal, 80(3): 516-526.

Daneshbakhsh, B., A. H. Khoshgoftarmanesh, H. Shariatmadari and I. Cakmak, 2013. Effect of zinc nutrition on salinityinduced oxidative damages in wheat genotypes differing in zinc deficiency tolerance. Acta physiologiae plantarum, 35(3): 881-889.

De Vries, F. T., R. I. Griffiths, M. Bailey, H. Craig, M. Girlanda, H. S. Gweon, S. Hallin, A. Kaisermann, A. M. Keith and M. Kretzschmar, 2018. Soil bacterial networks are less stable under drought than fungal networks. Nature communications, 9(1): 1-12.

Formentin, E., C. Sudiro, G. Perin, S. Riccadonna, E. Barizza, E. Baldoni, E. Lavezzo, P. Stevanato, G. A. Sacchi and P. Fontana, 2018. Transcriptome and cell physiological analyses in different rice cultivars provide new insights into adaptive and salinity stress responses. Frontiers in plant science, 9: 204.

Genc, Y., J. Taylor, G. Lyons, Y. Li, J. Cheong, M. Appelbee, K. Oldach and T. Sutton, 2019. Bread wheat with high salinity and sodicity tolerance. Frontiers in plant science, 10: 1280.

Goyal, E., S. K. Amit, R. S. Singh, A. K. Mahato, S. Chand and K. Kanika, 2016. Transcriptome profiling of the salt-stress response in Triticum aestivum cv. Kharchia local. Scientific reports, 6(1): 1-14.

Guo, R., Z. Yang, F. Li, C. Yan, X. Zhong, Q. Liu, X. Xia, H. Li and L. Zhao, 2015. Comparative metabolic responses and adaptive strategies of wheat (Triticum aestivum) to salt and alkali stress. BMC plant biology, 15(1): 1-13.

Hemida, K. A., R. M. Ali, W. M. Ibrahim and M. A. Sayed, 2014. Ameliorative role of some antioxidant compounds on physiological parameters and antioxidants responses of wheat (Triticum aestivum L.) seedling under salinity stress. Life science journal, 11(7): 324-342.
Iqra, L., M. Rashid, Q. Ali, I. Latif and A. Malik, 2020. Evaluation of genetic variability for salt tolerance in wheat. Biological clinical sciences research journal, 2020(1): e016-e016.

Isfahani, F. M., A. Tahmourespour, M. Hoodaji, M. Ataabadi and A. Mohammadi, 2018. Characterizing the new bacterial isolates of high yielding exopolysaccharides under hypersaline conditions. Journal of cleaner production, 185: 922-928.

Karthik, L., G. Kumar, T. Keswani, A. Bhattacharyya, S. S. Chandar and K. Bhaskara Rao, 2014. Protease inhibitors from marine actinobacteria as a potential source for antimalarial compound. PloS one, 9(3): e90972.

Khan, M. S., A. Rizvi, S. Saif and A. Zaidi, 2017. Phosphatesolubilizing microorganisms in sustainable production of wheat: Current perspective. In: Probiotics in agroecosystem. Springer: pp: 51-81.

Liu, S., S. Liu, M. Wang, T. Wei, C. Meng, M. Wang and G. J. T. P. C. Xia, 2014. A wheat similar to rcd-one gene enhances seedling growth and abiotic stress resistance by modulating redox homeostasis and maintaining genomic integrity. 26(1): 164180.

Masuda, K., 2016. Measuring eco-efficiency of wheat production in japan: A combined application of life cycle assessment and data envelopment analysis. ournal of cleaner production, 126: 373-381.

Miransari, M. and D. Smith, 2019. Sustainable wheat (Triticum aestivum l.) production in saline fields: A review. Critical reviews in biotechnology, 39(8): 999-1014.

Munns, R., D. A. Day, W. Fricke, M. Watt, B. Arsova, B. J. Barkla, J. Bose, C. S. Byrt, Z. H. Chen and K. J. Foster, 2020. Energy costs of salt tolerance in crop plants. New phytologist, 225(3): 1072-1090.

Nounjan, N., P. T. Nghia and P. Theerakulpisut, 2012. Exogenous proline and trehalose promote recovery of rice seedlings from salt-stress and differentially modulate antioxidant enzymes and expression of related genes. Journal of plant physiology, 169(6): 596-604.

Shah, Z. H., H. M. Rehman, T. Akhtar, I. Daur, M. A. Nawaz, M. Q. Ahmad, I. A. Rana, R. M. Atif, S. H. Yang and G. Chung, 2017. Redox and ionic homeostasis regulations against oxidative, salinity and drought stress in wheat (a systems biology approach). Frontiers in genetics, 8: 141.

Tiwari, B. K., A. Aquib and R. Anand, 2020. Analysis of physiological traits and expression of nhx and sos3 genes in bread wheat (Triticum aestivum L.) under salinity stress. Pharmaco phytochemistry, 9: 362-366.

Wang, M. and G. Xia, 2018. The landscape of molecular mechanisms for salt tolerance in wheat. The crop journal, 6(1): 42-47.

Xiong, H., H. Guo, Y. Xie, L. Zhao, J. Gu, S. Zhao, J. Li and L. Liu, 2017. Rnaseq analysis reveals pathways and candidate genes associated with salinity tolerance in a spaceflight-induced wheat mutant. Scientific reports, 7(1): 1-13.

Zarza, X., K. E. Atanasov, F. Marco, V. Arbona, P. Carrasco, J. Kopka, V. Fotopoulos, T. Munnik, A. Gómez-Cadenas and A. F. Tiburcio, 2017. Polyamine oxidase 5 loss-of-function mutations in arabidopsis thaliana trigger metabolic and transcriptional reprogramming and promote salt stress tolerance. Plant, cell environment, 40(4): 527-542. 
Zhang, Y., Z. Liu, A. A. Khan, Q. Lin, Y. Han, P. Mu, Y. Liu, H. Zhang, L. Li and X. Meng, 2016. Expression partitioning of homeologs and tandem duplications contribute to salt tolerance in wheat (Triticum aestivum L.). Scientific reports, 6(1): 1-10.

Zhao, Y., X. Ai, M. Wang, L. Xiao and G. Xia, 2016. A putative pyruvate transporter tabass2 positively regulates salinity tolerance in wheat via modulation of abi4 expression. BMC plant biology, 16(1): 1-12.

Zhao, Y., W. Dong, N. Zhang, X. Ai, M. Wang, Z. Huang, L. Xiao and G. Xia, 2014. A wheat allene oxide cyclase gene enhances salinity tolerance via jasmonate signaling. Plant physiology, 164(2): 1068-1076.

Except where otherwise noted, this item's licence is described as (C) The Author(s) 2021. Open Access. This item is licensed under a Creative Commons Attribution 4.0 International License, which permits use, sharing, adaptation, distribution and reproduction in any medium or format, as long as you give appropriate credit to the original author(s) and the source, provide a link to the Creative Commons license, and indicate if changes were made. The images or other third party material in this it are included in the article's Creative Commons license, unless indicated otherwise in a credit line to the material. If material is not included in the article's Creative Commons license and your intended use is not permitted by statutory regulation or exceeds the permitted use, you will need to obtain permission directly from the copyright holder. 